\title{
Active surveillance as a practical strategy to differentiate lethal and non-lethal prostate cancer subtypes
}

\author{
Yoshiyuki Kakehi
}

Differentiation between lethal and non-lethal prostate cancer subtypes has become a very important issue in avoiding excessive treatment in an era when prostate-specific antigen (PSA) screening has reduced the rate of prostate cancer deaths by more than $20 \%$. However, it is difficult to determine the patients who may or may not benefit from immediate treatment interventions at the time of the initial diagnosis. The selection of candidate patients who can postpone immediate treatment and undergo follow-ups with a specific surveillance program, or 'active surveillance,' is a practical way to minimize overtreatment. In this review, the benefits and risks of active surveillance are discussed. Future perspectives, including imaging and new biomarkers for improving the outcomes of active surveillance programs, are also discussed.

Asian Journal of Andrology (2012) 14, 361-364; doi:10.1038/aja.2011.151; published online 16 April 2012

Keywords: active surveillance; diagnosis; low risk; prostate cancer

\section{INTRODUCTION}

Prostate cancer is the second most frequently diagnosed cancer and the sixth leading cause of cancer deaths in males. Incidence rates vary by more than 25 -fold worldwide. ${ }^{1}$ The incidence rates of prostate cancer in Asian countries, including Japan, are much lower than the rates in Western countries. However, the incidence and mortality rates of prostate cancer in Japanese men have been increasing primarily due to changes in dietary habits and the increased use of prostate-specific antigen (PSA) testing. ${ }^{2}$ PSA testing is widely distributed in the United States, and approximately 240000 men were diagnosed with prostate cancer in 2011 in the United States. ${ }^{3}$ In the United States, prostate cancer accounts for $30 \%$ of all cancers in males. A total of 33720 men are expected to die of the disease in $2011 .^{3}$ These data clearly indicate that only a small fraction of the men diagnosed with prostate cancer actually die from the disease. The widespread use of PSA testing has resulted in an obvious stage migration, and prostate cancers are being detected earlier in their development. This lead time has been estimated to be 7-9 years based on results of the Baltimore Longitudinal Study on Aging. ${ }^{4}$ Two randomized studies evaluating the efficacy of screening for prostate cancer have recently reported interim results. The European Randomized Study of Screening for Prostate Cancer reported a $20 \%$ reduction in prostate cancer mortality. ${ }^{5}$ If non-compliance in the screening arm and contamination in the control arm of the study are taken into consideration, the mortality reduction would increase to $31 \% .^{6}$ In contrast, the American Prostate, Lung, Colorectal, Ovarian Cancer Screening Trial found that there were no survival benefits to screening. ${ }^{7}$ The results of the American Prostate, Lung, Colorectal, Ovarian Cancer trial were not conclusive because a substantial proportion of the study subjects, but only just over half of the control group, had previously undergone PSA testing. In addition, the number of prostate cancer deaths did not reach 100 due to a relatively short follow-up period.

Although the potential survival benefits of screening for prostate cancer have been demonstrated, we cannot ignore the risk of overdiagnosis, which inevitably results in overtreatment. Moreover, the survival benefits from prostate cancer screenings are uncertain in Asian men. Treating patients with cancers that would not otherwise cause clinical problems does not balance the risk of treatment complications, including urinary incontinence, sexual dysfunction and bowel dysfunction. Based on the results of the European Randomized Study of Screening for Prostate Cancer trial, over 1400 men would need to be screened to prevent one prostate cancer death. It was initially estimated that 48 patients would need to undergo treatment to prevent one prostate cancer death (number needed to treat). ${ }^{4}$ Although a subsequent estimation with additional follow-up demonstrated that the number needed to treat could be as low as 18 patients, ${ }^{8}$ approximately 20 patients with non-lethal prostate cancers should still be treated to save one patient from dying of prostate cancer in the contemporary PSA era. Therefore, it is imperative to establish a practical method of minimizing the overtreatment of patients with screendetected prostate cancer.

\section{ACTIVE SURVEILLANCE AS A STRATEGY TO AVOID OVERTREATMENT}

To select the patients who are assumed to have low grade, small cancer foci and postpone curative treatment until the patients show pathological progression by re-biopsy or an accelerated rise in PSA is the only practical way of avoiding possible overtreatment of prostate cancer. This treatment strategy, called active surveillance (AS), has not been fully accepted by both physicians and patients due to fear of 
progression of the lethal disease. ${ }^{9,10}$ However, the survival outcomes in a prospective single arm cohort study in Canada using AS were shown to be excellent. Only 5 out of the 450 patients in the cohort died from prostate cancer, with a median follow-up of 6.8 years. The 10 -year prostate cancer actuarial survival rate of this cohort was $97.2 \%{ }^{11}$ Similar survival outcomes have been demonstrated in a Japanese multicenter study in which one cancer death was observed out of 117 patients, with a median follow-up of 6.5 years. ${ }^{12,13}$

Generally, the selection criteria for patients in the prospective AS studies described are more stringent than those for cases of low-risk prostate cancer using the D'Amico's risk classification, as shown in Table $1^{11,12,14-16}$ The selection criteria for AS studies at Johns Hopkins University, the Japanese multicenter and the Prostate Cancer Research International: Active Surveillance (PRIAS) consist of a restriction on the number of positive cores (i.e., one or two positive cores per $6-12$ systematic cores). ${ }^{12,14,15}$ The selection criteria of the Johns Hopkins and Japanese studies required less than $50 \%$ cancer involvement in the positive cores. ${ }^{12,14}$ These criteria have influenced the currently revised National Comprehensive Cancer Network guidelines in which AS is recommended as a definitive option for patients with a life expectancy of less than 20 years who harbor 'very low risk' clinical features. However, patients with low-risk cancers who show favorable biopsy features and patients with other low-risk cancers, as well as some intermediate-risk cancers, may also be managed using AS based on the estimation of number needed to treat. Outcomes of AS in intermediate-risk patients treated at the University of California, San Francisco were comparable to the outcomes of the low-risk patients. ${ }^{17}$

\section{DIFFICULTY IN RISK ASSESSMENT USING BASELINE BIOPSIES ALONE}

A substantial percentage of the patients who fit the stringent criteria for AS at diagnosis have unfavorable pathological features in their prostates. In approximately $20 \%$ of the patients who qualified for AS but underwent an immediate prostatectomy, large cancer foci or capsular penetration were found, and the Gleason score increased from 6 to 7 or higher. ${ }^{13,18-20}$ To compensate for the possible underestimation of the baseline biopsy, the current protocols for AS include repeat prostate biopsies at predefined intervals, as shown in Table 2. ${ }^{11,15}$ According to the interim report on the 1-year repeat biopsy in the PRIAS study, $21.5 \%$ of 757 patients were reclassified as having a higher cancer risk. ${ }^{21}$ One-third of the Japanese AS cohort were also reclassified to a higher risk classification after the 1-year biopsy. ${ }^{12}$ These results clearly indicate the difficulty in risk assessment using baseline biopsies. To overcome the underestimation of baseline biopsies, multiple core biopsies have been investigated to ensure accurate diagnosis of non-lethal cancers. An AS cohort $(n=101)$ in the United Kingdom (age $\leqslant 75$ years, Gleason score $\leqslant 3+3$, $\mathrm{PSA} \leqslant 15 \mathrm{ng} \mathrm{ml}^{-1}$, clinical stage $\mathrm{T} 1-\mathrm{T} 2 \mathrm{a}, \leqslant 50 \%$ positive core ratio and cancer foci $\leqslant 10 \mathrm{~mm}$ in a single core) underwent a transperineal template prostate biopsy. One-third of the patients showed the presence of additional significant cancer as a result of this re-assessment. ${ }^{22}$ It remains controversial as to whether the template or saturation biopsies contribute to the accurate diagnosis of tumor localization. ${ }^{23}$

\section{DETECTION OF POTENTIALLY LETHAL CANCERS WITH IMAGING}

The role of MRI in the diagnosis and staging of prostate cancer has been extensively explored. High-resolution T2-weighted imaging (T2WI) using an endorectal coil provides an excellent depiction of the prostatic zonal anatomy with the peripheral zone, which shows a greater signal intensity than the central gland. ${ }^{24} \mathrm{~T} 2 \mathrm{WI}$ is limited in its use for detecting cancer foci in the central gland due to relatively low segregation between cancer and normal tissues. Considerable variations in the sensitivity $(22 \%-85 \%)$ and specificity $(50 \%-99 \%)$ of T2WI for the detection of prostate cancer have been reported. ${ }^{25} \mathrm{~A}$ retrospective survey in an AS cohort regarding the ability of endorectal T2WI to differentiate between favorable and adverse pathologic features yielded unsatisfactory results. ${ }^{26}$ Due to the relatively low specificity $(54 \%-82 \%)$ and widely variable sensitivity (46\%-96\%) of T2WI in determining tumor localization, ${ }^{27-29}$ other MRI sequences have been developed. Diffusion-weighted imaging, dynamic contrastenhanced MRI and MR spectroscopy appear to have strong potential for detecting the unfavorable features of cancer foci in the prostate, ${ }^{30}$ although none are used in routine clinical practice. The results of a prospective single institutional study on the combined assessment of 3.0-T endorectal MRI sequences, including T2WI, spectroscopic, dynamic contrast-enhanced and diffusion weighted imaging, fused with a transrectal ultrasonography-guided biopsy, showed improved detection of prostate cancer. ${ }^{31}$ Comprehensive assessments using multiple parameters of MRI sequences may improve the diagnostic accuracy of the prostate biopsy.

Transrectal ultrasonography is used in the routine practice of monitoring patients with AS more frequently than MRI. The role of serial transrectal ultrasonography in AS or watchful waiting patients has been reported to be of limited value as a determinant of disease progression. ${ }^{32}$ Contrast-enhanced ultrasonography has emerged as a promising new imaging modality to detect aggressive prostate cancer foci. ${ }^{33}$ A prospective randomized trial demonstrated improved tumor detection using contrast-enhanced ultrasonography. ${ }^{34}$ Additional

Table 1 Selection criteria in prospective active surveillance studies

\begin{tabular}{|c|c|c|c|c|c|}
\hline & Johns Hopkins University ${ }^{14}$ & University of Toronto ${ }^{11}$ & PRIAS ${ }^{15}$ & $U C S F^{16}$ & Japanese Multicenter ${ }^{12}$ \\
\hline cT stage & $T 1 c$ & T1c & $T 1 c$ or $T 2$ & T1 or T2a & $T 1 c$ \\
\hline $\begin{array}{l}\text { PSA (ng } \mathrm{ml}^{-1} \text { ) at } \\
\text { diagnosis }\end{array}$ & Not defined & $\begin{array}{l}\leqslant 10-15(1995-1999) \leqslant 10 \\
\quad(2000-2003)\end{array}$ & $\leqslant 10$ & $\leqslant 10$ & $\leqslant 20$ \\
\hline Gleason score & $\leqslant 3+3$ & $\begin{array}{l}\leqslant 3+3(\leqslant 3+4 \text { in men }>70 \\
\text { years until } 1999)\end{array}$ & $\leqslant 3+3$ & $\leqslant 3+3$ & $\leqslant 3+3$ \\
\hline $\begin{array}{l}\text { PSA density (ng ml } \mathrm{ml}^{-1} \\
\mathrm{ml}^{-1} \text { ) }\end{array}$ & $\leqslant 0.15$ & Not defined & $\leqslant 0.2$ & Not defined & Not defined \\
\hline $\begin{array}{l}\text { Maximal number of } \\
\text { positive cores }\end{array}$ & 2 & 2 (total core number: any) & $2\left(8-12\right.$ cores $\left.^{a}\right)$ & $<33 \%$ biopsy cores & 2 (6-12 cores) \\
\hline$\%$ cancer involvement & $<50 \%$ cancer in any core & $<50 \%$ cancer in any core & Not defined & $<50 \%$ cancer in any core & $<50 \%$ cancer in any core \\
\hline
\end{tabular}

Abbreviations: PRIAS, the Prostate Cancer Research International: Active Surveillance; PSA, prostate-specific antigen; UCSF, University of California, San Francisco.

${ }^{a}$ Necessary biopsy cores are defined depending on the prostate volume. 
Table 2 Follow-up protocols and triggers indicating initiation of radical treatment in prospective active surveillance studies

\begin{tabular}{|c|c|c|c|c|c|}
\hline & $\begin{array}{l}\text { Johns Hopkins } \\
\text { University }^{14}\end{array}$ & University of Toronto ${ }^{11}$ & $P R I A S^{15}$ & $\mathrm{UCSF}^{16}$ & Japanese Multicenter $^{12}$ \\
\hline PSA check & 6 monthly & 3 monthly & 3 monthly & 3 monthly & 3 monthly \\
\hline DRE check & 6 monthly & 6 monthly & 6 monthly & n.d. & 6 monthly \\
\hline TRUS check & n.d. & n.d. & n.d. & 6-12 months & 6 monthly \\
\hline Repeat biopsy & Annually & $\begin{array}{l}\text { 6-12 months after AS and } \\
\text { every 2-3 years thereafter }\end{array}$ & $\begin{array}{l}1 \text { year after AS. PSA-DT } \\
\text { >10years: every } 3 \text { years } \\
\text { thereafter; PSA-DT: } \\
\text { 3-10 years annually }\end{array}$ & Every $1-2$ years & 1 year after AS \\
\hline $\begin{array}{l}\text { Trigger for active } \\
\text { treatment }\end{array}$ & $\begin{array}{l}\text { Repeat biopsy: } \\
\text { reclassification }\end{array}$ & $\begin{array}{l}\text { PSA-DT }<3 \text { years } \\
\text { Repeat biopsy: } \\
\text { reclassification }\end{array}$ & $\begin{array}{l}\text { PSA-DT }<3 \text { years } \\
\text { Repeat biopsy: } \\
\text { reclassification }\end{array}$ & $\begin{array}{l}\text { PSAV }>0.75 \\
\text { Repeat biopsy: } \\
\text { reclassification }\end{array}$ & $\begin{array}{l}\text { PSA-DT }<2 \text { years } \\
\text { Repeat biopsy: } \\
\text { reclassification }\end{array}$ \\
\hline
\end{tabular}

Abbreviations: DRE, digital rectal exam; n.d., not defined; PRIAS, the Prostate Cancer Research International: Active Surveillance; PSA, prostate-specific antigen; PSA-DT, PSA doubling time; TRUS, transrectal ultrasonography; UCSF, University of California, San Francisco.

prospective studies are needed to clarify the usefulness of contrastenhanced ultrasonography in selecting good candidates for AS.

\section{ROLE OF PSA KINETICS IN THE FOLLOW-UP OF AS PATIENTS}

It is hard to predict the lethality of prostate cancer using initial PSA scores and baseline biopsies. The watchful waiting cohorts during the pre-PSA era, particularly patients with low-grade cancers, had very favorable survival outcomes, indicating that most men with low-risk prostate cancer have a substantial amount of time to monitor changes in their PSA. The AS protocol includes the PSA doubling time (PSADT) as a trigger to initiate aggressive treatment, as shown in Table 1. The pathological findings of radical prostatectomies in a Japanese AS cohort revealed that unfavorable pathological features of surgical specimens were more frequently observed in patients who underwent prostatectomies due to a short PSA-DT or reclassification by re-biopsy than in those who underwent prostatectomies due to other reasons, including the patients' preference. ${ }^{13}$ An interim report from PRIAS after a 1year re-biopsy and PSA-DT testing revealed that a PSA-DT shorter than 3 years was significantly associated with reclassification to a higher risk category. ${ }^{21}$ Researchers at Johns Hopkins University reported that PSA kinetics, including PSA-DT and PSA velocity, during the followup of AS patients, were not a reliable trigger for treatment intervention. ${ }^{35}$ It is obvious that PSA kinetics alone are not adequate for extracting the patients who require treatment intervention.

\section{BIOMARKERS FOR THE PREDICTION OF LETHAL CANCERS}

New biomarkers are being sought for predicting the lethality of prostate cancer. Translocation is a less common event in solid cancers than hematological cancers. However, the TMPRSS2 and ERG fusion gene is present in up to $50 \%$ of prostate cancer cases. ${ }^{36}$ The fusion gene has been associated with aggressive histological patterns. ${ }^{37}$ The association of the fusion gene with poor survival outcomes has been reported in a watchful waiting cohort. ${ }^{38}$ Another research group reported that fusion-positive tumors were associated with a lower Gleason grade and better survival outcomes. ${ }^{39}$ Immunohistochemical and FISH analyses on tissue microarrays of more than 2800 prostatectomy specimens revealed that the TMPRSS2-ERG fusion gene was unrelated to clinical outcomes and tumor phenotypes. ${ }^{40}$ Since the significance of the TMPRSS2-ERG fusion gene in prostate cancer remains controversial, additional studies are needed to clarify its clinical usefulness. Urine is a potential source of biomarkers for prostate cancer. PCA3, formerly called DD3, is a non-coding RNA specifically secreted from prostate cancer cells. ${ }^{41}$ Clinical studies have demonstrated the usefulness of urinary PCA3 detection for the diagnosis of prostate cancer, although the function of PCA3 has not been elucidated. ${ }^{42,43}$ Ploussard et al. ${ }^{44}$ demonstrated a strong correlation between the urinary PCA3 score and tumor volume in prostatectomy specimens, and the PCA3 test can assist in the selection of better candidates for AS. These results appear to be reasonable because PCA3 is only overexpressed in prostate cancer cells. However, the study does not demonstrate a direct association between the urine PCA3 score and malignant potentials, such as a high Gleason grade and extracapsular extension. The engrailed-2 protein, a transcription factor secreted by prostate cancer cells, is another candidate biomarker for prostate cancer in the urine. Engrailed-2 is measured without digital rectal exam and appears to have a high predictability for prostate cancer. ${ }^{45}$ Although it is unclear how prostate cancer cells occur in voided urine, urine biomarkers are ideal because they are sampled non-invasively. Therefore investigating the usefulness of urine biomarkers for monitoring clinical progression in patients in AS programs is recommended.

\section{CONCLUSIONS}

AS is a practical option for minimizing overtreatment in patients with screen-detected prostate cancer. The current AS protocols require periodic repeat biopsies due to the low reliability of PSA kinetics. New serum or urine biomarkers that predict the aggressiveness and lethality of prostate cancer will make AS a more feasible and safe option.

\section{COMPETING FINANCIAL INTERESTS}

The author declares no competing financial interests.

1 Jemal A, Bray F, Center MM, Ferlay J, Ward E et al. Global cancer statistics. CA Cancer J Clin 2011; 61: 69-90.

2 Ito Y, loka A, Tanaka M, Nakayama T, Tsukuma H. Trends in cancer incidence and mortality in Osaka, Japan: evaluation of cancer control activities. Cancer Sci 2009, 100: 2390-5.

3 Siegel R, Ward E, Brawley O, Jemal A. Cancer statistics, 2011. CA Cancer J Clin 2011; 61: 212-36

4 Pearson JD, Carter HB. Natural history of changes in prostate specific antigen in early stage prostate cancer. J Urol 1994; 152: 1743-8.

5 Schroeder FH, Hugosson J, Roobol MJ, Tammela TL, Ciatto S et al. Screening and prostate-cancer mortality in a randomized European study. N Engl J Med 2009; 360: $1320-8$.

6 Roobol MJ, Kerkhof M, Schröder FH, Cuzick J, Sasieni P et al. Prostate cancer mortality reduction by prostate-specific antigen-based screening adjusted for nonattendance and contamination in the European Randomized Study of Screening for Prostate Cancer (ERSPC). Eur Urol 2009; 56: 584-91.

7 Andriole GL, Crawford ED, Grubb RL3rd, Buys SS, Chia D et al. Mortality results from a randomized prostate-cancer screening trial. N Engl J Med 2009; 360: 1310-9. 
8 Loeb S, Vonesh EF, Metter EJ, Carter HB, Gann PH et al. What is the true number needed to screen and treat to save a life with prostate-specific antigen testing? J Clin Oncol 2011; 29: 464-7.

9 Cooperberg MR, Broering JM, Kantoff PW, Carroll PR. Contemporary trends in low risk prostate cancer: risk assessment and treatment. J Urol 2007; 178 (3 Pt 2): s14-9.

10 Anandadas CN, Clarke NW, Davidson SE, O'Reilly PH, Logue JP et al. Early prostate cancer-which treatment do men prefer and why? BJU Int 2010; 107: 1762-8.

11 Klotz L, Zhang L, Lam A, Nam R, Mamedov A, et al. Clinical results of long-term followup of a large, active surveillance cohort with localized prostate cancer. J Clin Oncol 2010; 28: 126-31.

12 Kakehi Y, Kamoto T, Shiraishi T, Ogawa O, Suzukamo Y et al. Prospective evaluation of selection criteria for active surveillance in Japanese patients with stage T1cNOMO prostate cancer. Jpn J Clin Oncol 2008; 38: 122-8.

13 Sugimoto M, Shiraishi T, Tsunemori H, Demura T Saito Y et al. Pathological findings at radical prostatectomy in Japanese prospective active surveillance cohort. Jpn J Clin Oncol 2010; 40: 973-9.

14 Carter HB, Kettermann A, Warlick C, Metter EJ, Landis P et al. Expectant management of prostate cancerwith curative intent: an update of Johns Hopkins experience. J Urol 2007; 178: 2359-64.

15 van den Bergh RC, Roemeling S, Roobol MJ, Roobol W, Schröder FH et al. Prospective validation of active surveillance in prostate cancer: the PRIAS study. Eur Urol 2007; 52: 1560-3.

16 Dall'Era MA, Konety BR, Cowan JE, Shinohara K, Stauf F et al. Active surveillance for the management of prostate cancer in a contemporary cohort. Cancer 2008; 112: 2664-70.

17 Cooperberg MR, Cowan JE, Hilton JF, Reese AC, Zaid HB et al. Outcomes of active surveillance for men with intermediate-risk prostate cancer. J Clin Oncol 2011; 29: 228-34.

18 Pinthus JH, Witkos M, Fleshner NE, Sweet J, Evans A et al. Prostate cancers scored as Gleason 6 on prostate biopsy are frequently Gleason 7 tumors at radical prostatectomy: implication on outcome. J Urol 2006; 176: 979-84.

19 Lee MC, Dong F, Stephenson AJ, Jones JS, Magi-Galluzzi C et al. The Epstein criteria predict for organ-confined but not insignificant disease and a high likelihood of cure at radical prostatectomy. Eur Urol 2010; 58: 90-5.

20 Jeldres C, Suardi N, Walz J, Hutterer GC, Ahyai S et al. Validation of the contemporary Epstein criteria for insignificant prostate cancer in European men. Eur Urol 2008; 54: $1306-13$.

21 Bul M, van den Bergh RC, Rannikko A, Valdagni R, Pickles T et al. Predictors of unfavourable repeat biopsy result in men participating in a prospective active surveillance program. Eur Urol 2012; 61: 370-7.

22 Ayres BE, Montgomery BS, Barber NJ, Pereira N, Langley SE et al. The role of transperineal template prostate biopsy in restaging men with prostate cancer managed by active surveillance. BJU Int; e-pub ahead of print 19 August 2011; doi: 10.1111/j.1464-410X.2011.10480.x.

23 Sartor O. Prostate cancer. Saturation biopsy does not accurately localize tumors. Nat Rev Urol 2010; 7: 479-80.

24 Kurhanewicz J, Vigneron DB, Hricak H, Narayan P, Carroll P et al. The prostate: MR imaging and spectroscopy. Present and future. Radiol Clin North Am 2000; 38: 115-38.

25 Turkbey B, Albert PS, Kurdziel K, Choyke PL. Imaging localized prostate cancer: current approaches and new developments. Am J Roentgenol 2000; 102: 1471-80.

26 Guzzo TJ, Resnick MJ, Canter DJ, Bivalacqua TJ, Rosen MA et al. Endorectal T2. weighted MRI does not differentiate between favorable and adverse pathologic features in men with prostate cancer who would qualify for active surveillance. Urol Oncol; e-pub ahead of print 17 August 2011; doi:10.1016/j.urolonc.2010.08.023.

27 Kirkham AP, Emberton M, Allen C. How good is MRI at detecting and characterizing cancer within the prostate? Eur Urol 2006; 50: 1163-74.
28 Engelbrecht MR, Jager GJ, Laheij RJ, Verbeek AL, van Lier HJ et al. Local staging of prostate cancer using magnetic resonance imaging: a meta-analysis. Eur Radiol 2002; 12: 2294-302

29 Wefer AE, Hricak H, Vigneron DB, Coakley FV, Lu Y et al. Sextant localization of prostate cancer: comparison of sextant biopsy, magnetic resonance imaging and magnetic resonance spectroscopic imaging with step section. J Urol 2000; 164: 400-4.

30 Choi S. The role of magnetic resonance imaging in the detection of prostate cancer. $J$ Urol 2011; 186: 1281-5.

31 Pinto PA, Chung PH, Rastinehad AR, Baccala Jr, AA, Kruecker J et al. Magnetic resonance imaging/ultrasound fusion guided prostate biopsy improve cancer detection following transrectal ultrasound biopsy and correlates with multiparametric magnetic resonance imaging. J Urol 2011; 186: 1281-5.

32 Hruby G, Choo R, Klotz L, Danjoux C, Murphy J et al. The role of serial transrectal ultrasonography in a 'watchful waiting' protocol for men with localized prostate cancer. BJU Int 2001; 87: 643-7.

33 Mitterberger M, Aigner F, Pinggera GM, Steiner E, Rehder P et al. Contrast-enhanced colour Doppler-targeted prostate biopsy: correlation of a subjective blood-flow rating scale with the histopathological outcome of the biopsy. BJU Int 2010; 106: 1315-8.

34 Mitterberger M, Horninger W, Pelzer A, Strasser H, Bartsch G et al. A prospective randomized trial comparing contrast-enhanced targeted versus systematic ultrasound guided biopsies: impact on prostate cancer detection. Prostate 2007; 67: 1537-42.

35 Ross AE, Loeb S, Landis P, Partin AW, Epstein Jl et al. Prostate-specific antigen kinetics during follow-up are an unreliable trigger for intervention in a prostate cancer surveillance program. J Clin Oncol 2010; 28: 2810-6.

36 Tomlins SA, Rhodes DR, Perner S, Dhanasekaran SM, Mehra R et al. Recurrent fusion of TMPRSS2 and ETS transcription factor genes in prostate cancer. Science 2005; 310: 644-8.

37 Mosquera JM, Perner S, Demichelis F, Kim R, Hofer MD et al. Morphological features of TMPRSS2-ERG gene fusion prostate cancer. J Pathol 2007; 312: 91.

38 Demichelis F, Fall K, Perner S, Andrén O, Schmidt F et al. TMPRSS2: ERG gene fusion associated with lethal prostate cancer in a watchful waiting cohort. Oncogene 2007; 26: 4596 .

39 Winners M, Lissbrant E, Damber JE, Stenman G. Molecular genetic analyses of the TMPRSS2-ERG and TMPRSS2-ETV1 gene in 50 cases of prostate cancer. Oncol Rep 2007; 17: 1033 .

40 Minner S, Enodien M, Sirma H, Luebke AM, Krohn A et al. ERG status is unrelated to $\mathrm{PSA}$ recurrence in radically operated prostate cancer in the absence of antihormonal therapy. Clin Cancer Res 2011; 17: 5878-88.

41 Bussemakers MJ, VanBokhoven A, Verhaegh GW, Smit FP, Karthaus HF et al. DD3: a new prostate-specific gene, highly overexpressed in prostate cancer. Cancer Res 1999; 59: 5975-9

42 Groskopf J, Aubin SM, Deras IL, Blase A, Bodrug S et al. APTIMA PCA3 molecular urine test: development of a method to aid in the diagnosis of prostate cancer. Clin Chem 2006; 52: 1089-95

43 Aubin SM, Reid J, Sarno MJ, Blase A, Aussie J et al. Prostate cancer gene 3 score predicts prostate biopsy outcome in men receiving dutasteride for prevention of prostate cancer: results from the REDUCE trial. Urology 2011; 78: 380-5.

44 Ploussard G, de la Taille A, Bayoud Y, Durand X, Terry S et al. Prostate cancer antigen 3 score accurately predicts tumor volume and might help in selecting prostate cancer patients for active surveillance. Eur Urol 2011; 59: 422-9.

45 Morgan R, Boxall A, Bhatt A, Bailey M, Hindley R et al. Engrailed-2 (EN2): a tumor specific urinary biomarker for the early diagnosis of prostate cancer. Clin Cancer Res 2011; 17: 1090-8. 